\title{
La Société Internationale et les Grandes Pandémies
}

\author{
Sandrine Maljean-Dubois e Rostane Mehdi (Orgs.) \\ A. Pedone, Paris, 2007
}

\author{
Deisy Ventura(*) \\ Marcelo da Silva ${ }^{(* *)}$
}

Uma pandemia é um fenômeno patológico que alcança simultaneamente um grande número de pessoas, numa zona geográfica muito vasta. Tanto a pandemia como a epidemia consistem num forte aumento de casos de uma dada enfermidade. Porém, a pandemia diferencia-se da epidemia justamente por sua maior dimensão, seja por sua propagação territorial, seja pela gravidade da ocorrência, o que resulta num número expressivo de casos severos ou mortes, em também numerosos países.

Desnecessário, então, sublinhar que a substituição de uma palavra pela outra, no jargão das organizações internacionais, por si só denota o desejo de chamar a atenção para a comunhão de destino que caracteriza a sociedade de risco - perceba-se o salto já na origem etimológica dos termos, passando daquilo que circula entre o povo de um lugar (epidemia) àquilo que concerne toda a gente (pandemia).

Com efeito, a atual aceleração geométrica da circulação de pessoas e de bens traz ao conceito de pandemia incontáveis aspectos que potencializam sua complexidade. Para limitarmo-nos, de início, ao ponto de vista técnico, há a dificuldade de delimitação do território atingido, enquanto uma epidemia se concentra numa zona geográfica precisa; e também são, hoje, no mínimo discutíveis a similaridade e a excepcionalidade das condições a que se submeteram os indivíduos contaminados. Assim, embora não se trate de uma novidade histórica, o tema das pandemias vincula-se fortemente à evolução contemporânea da globalização econômica, pela velocidade presente de todos os intercâmbios.

(*) Doutora em Direito da Universidade de Paris 1 (Panthéon-Sorbonne), Professora do Programa de Pós-graduação em Direito da Universidade do Vale do Rio dos Sinos (UNISINOS) e Pesquisadora do CEPEDISA/USP. E-mail: <deisyflv@gmail.com>.

$\left.{ }^{(*}\right)$ Mestre em Letras e Bacharel em Direito pela Universidade Federal de Santa Maria (UFSM), Professor do Universus Language International e École de Langue Française pour étrangers, Bolsista do CEPEDISA/USP. E-mail: <prof.marcelo.silva@uol.com.br>. Recebido em 31.5.08. 
Também de espinhosa conceituação, a sociedade internacional (aqui entendida para além dos Estados e das organizações internacionais, compreendendo os entes não estatais e os indivíduos) procura reagir a estes riscos que fervilham e pululam, intensa e rapidamente, pelo globo. A obra ora resenhada consiste numa resposta preliminar da academia a este gigantesco desafio. Trata-se do resultado do $14^{\circ}$ Encontro Internacional de Aix-enProvence, França, organizado pelo Instituto de Estudos Políticos daquela cidade, sobre a relação entre a multiplicação das trocas e contatos humanos, e o risco de propagação internacional de doenças infecciosas. Na ordem do dia dos autores, encontra-se a necessidade de adoção de dispositivos de prevenção e de ação, que favoreçam o tratamento das "crises sanitárias" no âmbito internacional.

As duas centenas de páginas do livro estruturam-se sobre três eixos: 1) a prevenção das pandemias; 2) a urgência sanitária internacional; e 3) a condição de bem público mundial atribuída à saúde. Uma introdução de Jean Salmon (Universidade de Bruxelas) aponta as principais pandemias que já acometeram a humanidade e elenca as que se afiguram como emergentes. Na ótica do autor, o direito internacional da saúde assenta sobre numerosas contradições, sobretudo a de que a sociedade internacional é governada pelo liberalismo, no qual tudo se mede em termos de proveito e de privatização, enquanto o combate às pandemias requer um modelo de desenvolvimento econômico baseado na solidariedade.

A primeira parte do livro traz, entre outros, o renomado Michel Bélanger (Universidade de Bordeaux), que ali se dedica à demonstração do papel histórico da Organização Mundial da Saúde em matéria de prevenção das pandemias. Contudo, ele denuncia "uma globalização imperfeita das atividades normativas preventivas" e uma "conceitualização incompleta", embora reconheça que as ações de prevenção merecem cada vez maior relevância na cena internacional.

Ainda na primeira parte, encontra-se a análise do caso da luta contra o HIV/AIDS na Argélia; uma entrevista com Rony Brauman, Presidente honorário da organização Médicos sem Fronteiras, sobre os desafios sanitários da ajuda ao desenvolvimento; e um estudo sobre a ação internacional que visa à repressão do bioterrorismo, sublinhando a crescente demanda de vigilância epidemiológica e de rapidez do alerta quando se trata deste tipo de criminalidade.

A segunda parte da obra, voltada à urgência sanitária internacional, debruça-se sobre o crucial tema da implementação do Regulamento Sanitário Internacional, questionando a eficácia das ferramentas de reação da OMS. O caso do SRAS e da gripe aviária e o sistema de gestão de crise empregado nestes dois casos constituem objeto de especial interesse dos autores convidados. São enfocadas, igualmente, as organizações regionais, pondo em relevo sua capacidade de secundar a atuação da OMC, trazendo o exemplo concreto da União Européia. 
Enfim, em sua terceira e última parte, o livro afirma a funcionalidade do conceito de bem público internacional, cada vez mais difundido em matéria de saúde. Jean-Marc Sorel (Universidade de Paris 1) procura definir esta expressão (mais uma) arduamente polissêmica: bem público internacional pode ser tanto um conceito dotado de valor normativo, ligado a uma convenção (como o patrimônio cultural mundial) ou a uma organização (como a Autoridade de Fundos Marinhos), como um conceito declaratório sob a forma de uma espécie de voto ou desejo, numa "língua de algodão" cujas palavras merecem a concordância terna de todos. Ele conclui que poucos são os bens públicos mundiais no sentido de que podem ser oponíveis a todos, e devem ser geridos segundo o interesse coletivo. Que a saúde deve ser um deles, parece evidente. Entretanto, saber se a condição de "bem" configura uma cláusula programática ou um corpus juris, trata-se de um debate ainda em aberto, opondo Estados, setores da economia e sociedade. Entre os demais artigos que instruem esta terceira seção, destaca-se o do brasileiro Marcelo Dias Varella (Centro Universitário de Brasília - UniCEUB) sobre o caso do acesso aos medicamentos, que evidencia as conseqüências práticas da interpretação do referido conceito.

As conclusões deste livro recomendam circunspecção e severidade, mas também causam um fascínio legítimo. Talvez a obra de Camus seja um dos espectros literários mais presentes na reflexão sobre as pandemias, lembrando que os homens jamais serão livres enquanto existirem flagelos e que as pragas são bem mais do que pesadelos - ademais, de pesadelo em pesadelo, são os homens que passam, sobretudo os humanistas, por falta de precaução.

Por tudo isto, não resta dúvida sobre o fato de que as pandemias são um grande canteiro de obras temático para as ciências humanas e sociais e que de nossa capacidade de resposta depende, em grande parte, a qualidade da reação humana à catástrofe sanitária em grande escala. Somos nós aqueles que forjarão o caldo de idéias a orientar a ação e a opinião públicas. Há o impacto econômico das pandemias, como a queda dos níveis de produção e consumo, e as restrições ao comércio. Mas há, sobretudo, a repercussão que afeta a condição humana. Não somente o acesso à saúde, mas a liberdade de ir e vir e de trabalhar estão em questão. Ademais, os seres humanos não se encontram em condições de igualdade frente à peste: um abismo, tanto no plano da informação como no que tange ao acesso a bens materiais, os aparta brutalmente em distintos grupos.

Nesta dimensão ética, não podemos deixar de incluir a incidência do modo de vida peculiar à sociedade de consumo como fator de agravamento dos riscos de pandemia, via crescente complexidade das doenças. Entre os que desfrutam da sociedade de consumo, há o uso irresponsável de medicamentos, o desperdício e a degradação ambiental. Entre os que não podem aceder à condição de consumidores, há a ausência de saneamento básico, a 
osmose entre homem e animal, a impossibilidade de combate ao inimigo desconhecido, a miséria que determina a absoluta fragilidade diante da doença.

Em qualquer caso, o reconhecimento do risco se impõe. Só o pensamento pode prevenir o pânico. Só a cooperação internacional pode evitar o caos. Este livro é um bom gatilho para disparar a urgente reflexão sobre as pandemias, particularmente no Brasil, país em que a implementação do Regulamento Sanitário Internacional, instrumento-chave da prevenção às pandemias, ainda não mereceu a devida atenção. 